\title{
Enhanced Uptake of Taurine by Basolateral Plasma Membrane Vesicles Isolated from Developing Rat Liver
}

\author{
JOHN C. BUCUVALAS, ANITA L. GOODRICH, AND FREDERICK J. SUCHY \\ Division of Gastroenterology, Children's Hospital Research Foundation, Cincinnati, Ohio; and Department of \\ Pediatrics, University of Cincinnati College of Medicine, Cincinnati, Ohio 45229
}

\begin{abstract}
Inasmuch as taurine biosynthesis is decreased during early postnatal life, an efficient mechanism for taurine uptake by the liver must be present to maintain intracellular stores of this $\beta$-amino acid. Therefore, basolateral liver plasma vesicles prepared from 14-day and adult rats were used to examine taurine transport during development. For both age groups, the presence of an inwardly directed $\mathrm{Na}^{+}$gradient stimulated the initial rate of taurine uptake and caused a transient accumulation of taurine above equilibrium. For all time points before equilibrium, taurine uptake was significantly greater with membrane vesicles from 14-day compared to adult rat livers. In contrast, no age-related differences in $\mathrm{Na}^{+}$-independent uptake as measured with a $\mathrm{K}^{+}$gradient were detected. With equal intravesicular and extravesicular $\mathrm{Na}^{+}$concentrations, taurine uptake remained significantly greater in the younger age group. For both age groups, $\mathrm{Na}^{+}$-dependent taurine uptake was saturable but the apparent $\mathrm{Km}$ and Vmax for $\mathrm{Na}^{+}$-dependent taurine uptake were significantly greater in membrane vesicles from 14-day compared to adult rats. These findings suggest that an increased number of functional carriers for taurine are present in developing compared to adult basolateral plasma membrane perhaps reflecting the needs of the immature liver for this essential nutrient. (Pediatr Res 23: 172-175, 1988)
\end{abstract}

Abbreviations
HEPES, N-2 hydroxyethylpiperazine-N-2-ethanesulfonic
acid
LPMV, liver plasma membrane vesicles
LPM, liver plasma membrane
CSAD, cysteine sulfinic acid decarboxylase

Taurine is the major free intracellular amino acid present in most tissues (1). Conjugation of bile acids with this $\beta$-amino acid has been well established and the proportion of taurine conjugates present in bile depends on species, stage of development, and substrate availability. Taurine may also participate in osmoregulation of cell volume and control of membrane excitability $(2,3)$.

Received June 30, 1987; accepted September 29, 1987

Correspondence Frederick J. Suchy, M.D., Children's Hospital Research Foundation, Elland and Bethesda Avenues, Cincinnati, OH 45229.

Supported by USPHS Grant HD20632 (F.J.S.), by a grant from the March of Dimes Birth Defects Foundation (F.J.S.), and by a National Research Service Award F32HD06705 (J.C.B.). The findings have been previously presented, in part, at the Society of Pediatric Research Annual Meeting in Washington, D.C. in May, 1985 .
The capacity to synthesize taurine is limited in the young of many mammals including the human $(4,5)$. Therefore, a substantial proportion of total body taurine stores in the fetus and neonate is derived from exogenous sources (6). The liver plays a central role in taurine homeostasis first as a respository for this substrate during the perinatal period and later as a major site of biosynthesis $(6,7)$. $\mathrm{A} \mathrm{Na}^{+}$-dependent cotransport mechanism for taurine has recently been demonstrated on the basolateral plasma membrane of rat liver and on the brush border membrane of rat jejunum $(8,9)$. Significantly higher rates of taurine transport were observed in brush border membrane vesicles isolated from suckling compared with adult rat jejunum (9). These findings further emphasize the contribution of diet as a source of taurine during development. Herein, we show that uptake of taurine by basolateral membrane vesicles from suckling rat liver is enhanced compared to rates of transport by membrane vesicles prepared from adult rat liver.

\section{MATERIALS AND METHODS}

Animals. Fourteen day old Sprague-Dawley rats with their dams or 200-250 g adult male Sprague-Dawley rats (Harlan Laboratories, Indianapolis, IN) were housed at a constant temperature $\left(22^{\circ} \mathrm{C}\right)$ with alternating 12 -h light/dark cycles. Adult male rats and mothers had free access to standard rat food and water. Adult male rats were killed between 0800 and $1000 \mathrm{~h}$ by exsanguination after being anesthesized with intraperitoneal pentobarbital. Suckling rats were killed by decapitation between 0800 and $1000 \mathrm{~h}$.

Chemicals. $\left[{ }^{3} \mathrm{H}\right]$-taurine $(29 \mathrm{Ci} / \mathrm{mmol})$ was purchased from Amersham (Arlington Heights, IL). Percoll and HEPES were obtained from Sigma Chemical Company (St. Louis, MO). All other chemicals were of reagent grade or of the highest quality commercially available.

Membrane vesicle preparation. Twenty to $25 \mathrm{~g}$ of liver were pooled from two to three adult male rats or from 30 to 35 pups who were 14 days old. Basolateral liver plasma membrane vesicles were prepared using a self-generating Percoll gradient method described by Blitzer and coworkers $(10,11)$ for the adult rat and validated in our laboratory for the neonatal and suckling rat. The final membrane product was enriched 25- to 30-fold in the basolateral membrane marker, $\mathrm{Na}^{+}, \mathrm{K}^{+}$, ATPase. Canalicular membrane markers $\mathrm{Mg}^{++}$ATPase and alkaline phosphatase were enriched only 3- to 5-fold and there was no enrichment of lysosomal, mitochondrial, or microsomal marker enzymes. The basolateral membrane domain represents 97 to $98 \%$ of the plasma membranes in the final membrane fraction. Transport studies were performed using membranes stored at $-70^{\circ} \mathrm{C}$ for up to $2 \mathrm{wk}$; previous studies in our laboratory have shown that transport properties of the vesicles are retained during storage for this period of time. Protein concentrations were determined 
according to the method of Lowry et al. (12) with bovine serum albumin as the standard.

Transport studies. Uptake of $\left[{ }^{3} \mathrm{H}\right]$-taurine was measured as previously described (8). Briefly $20 \mu \mathrm{l}$ of LPMV suspension $(10$ $\mathrm{mM}$ HEPES-KOH, pH 7.5, $300 \mathrm{mM}$ sucrose) containing 45-85 $\mu \mathrm{g}$ of protein were preincubated at $37^{\circ} \mathrm{C}$ in a water bath. Uptake was initiated by addition of $80 \mu \mathrm{l}$ of incubation buffer containing $\left[{ }^{3} \mathrm{H}\right]$-taurine and varying concentrations of unlabeled taurine or other amino acids to the membrane aliquot $(20 \mu \mathrm{l})$. The reaction mixture was vigorously mixed and timed uptakes at $37^{\circ} \mathrm{C}$ were terminated by addition of $3.5 \mathrm{ml}$ of iced cold stop solution. The sample was rapidly filtered through a $0.45-\mu \mathrm{m}$ Millipore filter. The test tube was washed again with $3.5 \mathrm{ml}$ stop solution, and the contents were filtered. Finally, the filter was washed twice with $3.5 \mathrm{ml}$ stop solution, dissolved in $4 \mathrm{ml}$ of Ready-Solv HP (Beckmann Instruments, Fullerton, CA), and counted in a scintillation counter. For all transport studies, uptakes were corrected for a blank in which $3.5 \mathrm{ml}$ of cold stop solution was added to the membrane aliquot before radiolabeled substrate. In addition, in order to reduce nonspecific binding of $\left[{ }^{3} \mathrm{H}\right]$-taurine to the filter, the filters were saturated with an excess of taurine $(3 \mathrm{ml}$ of $1 \mathrm{mM}$ taurine solution) prior to initiation of uptake.

Membrane vesicles were voltage clamped at $\mathrm{E}_{\mathrm{m}} \sim 0$ by establishing equal intravesicular and extravesicular concentrations of potassium $(50 \mathrm{mM})$ in the presence of valinomycin $\left(2.5 \mu \mathrm{g} \mathrm{mg}^{-1}\right.$ protein) added as a stock solution $(10 \mathrm{mg} / \mathrm{ml})$ in ethanol (final concentration $0.1 \%$ ). Preloading vesicles with $100 \mathrm{mM} \mathrm{NaCl}$ was performed by incubating an aliquot of LPM suspension with an equal volume of a solution containing $200 \mathrm{mM} \mathrm{NaCl}$ and 10 mM HEPES-KOH, pH 7.5 for $2 \mathrm{~h}$ at $25^{\circ} \mathrm{C}$.

Statistical methods. Unless otherwise stated, Figures 1-4 depict representative experiments in which uptakes were performed in triplicate. Each experiment was repeated at least twice using membrane prepared on different days. Student's $t$ test for un-

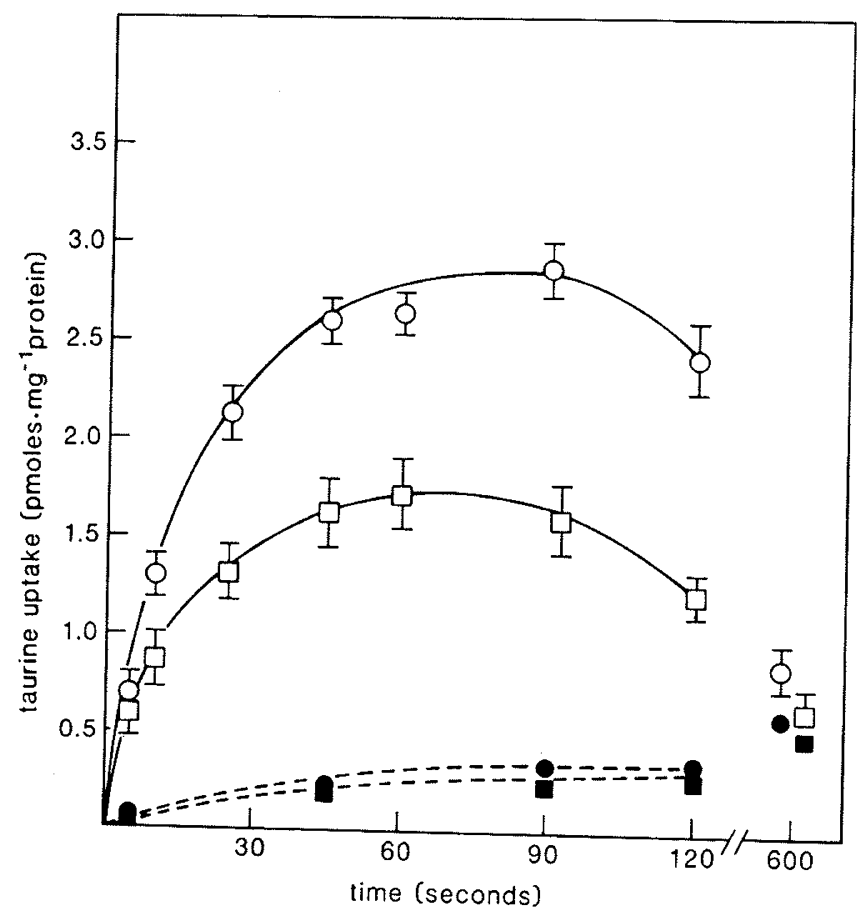

Fig. 1. Effect of an inwardly directed $100 \mathrm{mM} \mathrm{NaCl}$ (open symbols) or $\mathrm{KCl}$ (closed symbols) gradient on $\left[{ }^{3} \mathrm{H}\right]$-taurine $(1 \mu \mathrm{M})$ uptake at $37^{\circ}$ $\mathrm{C}$ using membrane vesicles prepared from 14-day or adult rat livers. Final reaction mixture and stop solution contain $100 \mathrm{mM} \mathrm{NaCl}$ or $\mathrm{KCl}$, $100 \mathrm{mM}$ sucrose, and $10 \mathrm{mM}$ HEPES-KOH, $\mathrm{pH}$ 7.5. Symbols represent the mean \pm SEM of triplicate determinations at each time point from a typical experiment. For some time points, the error bar is smaller than the symbol. $\square$, adult, $\bullet, 14$ day.

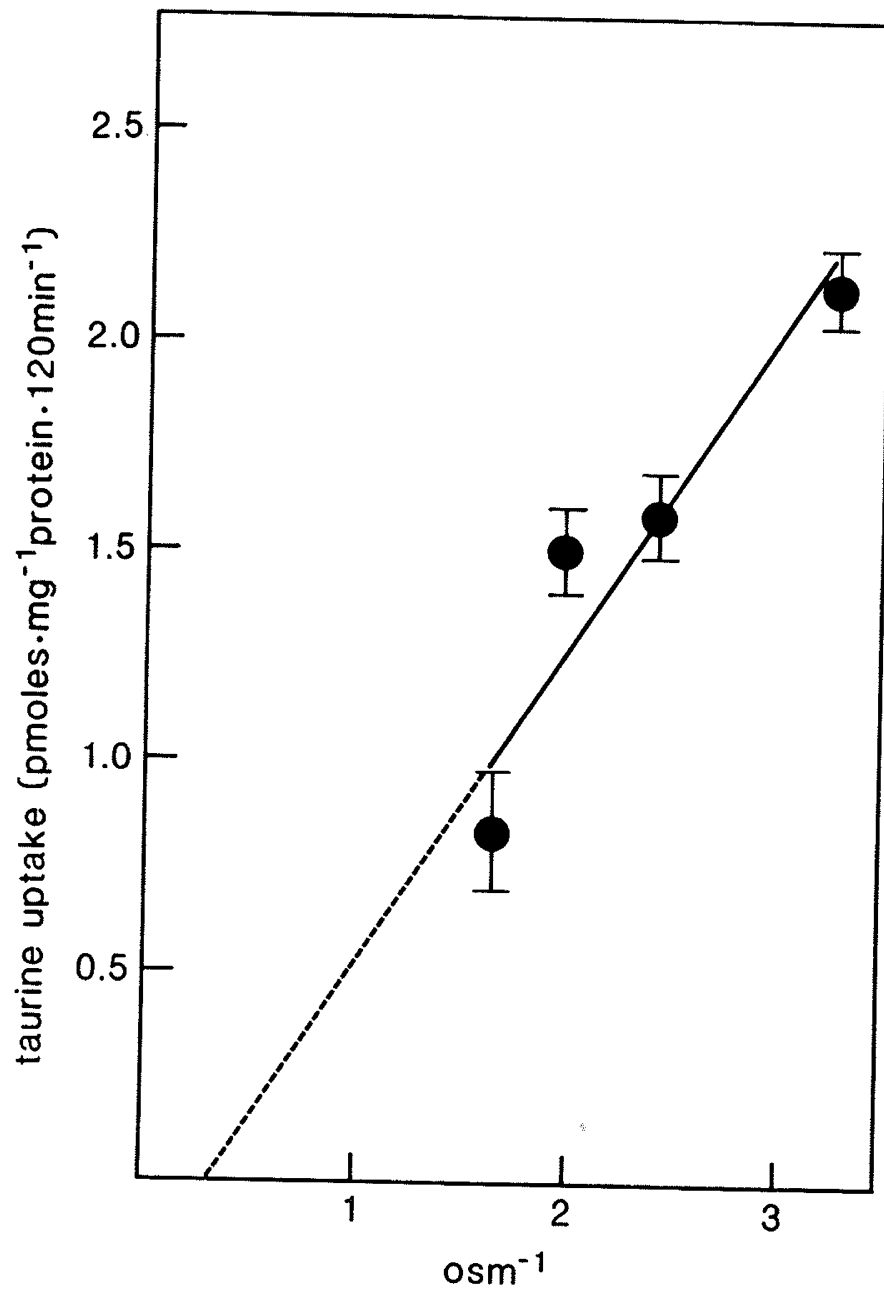

Fig. 2. Effect of medium osmolarity on equilibrium $(2 \mathrm{~h})$ uptake of $\left[{ }^{3} \mathrm{H}\right]$-taurine $(2 \mu \mathrm{M})$ at $37^{\circ} \mathrm{C}$. Reaction mixture and stop solutions contained $100 \mathrm{mM} \mathrm{NaCl}, 10 \mathrm{mM}$ HEPES-KOH, pH 7.5, $100 \mathrm{mM}$ sucrose, and varying concentrations of cellobiose (0 to $300 \mathrm{mM}$ ). Reaction mixture osmolarity was verified using an osmometer. Symbols represent the means \pm SEM of quadruplicate determinations from a typical experiment. Linear regression analysis of the means was performed.

paired samples was used to test the significance of differences among means. Kinetic data were analyzed using a computer program that performed a weighted least squares fit of individual data points to a rectangular hyperbola (13). Kinetic constants for taurine uptake using membrane vesicles from 14-day and adult rats were compared with a $Z$ test.

\section{RESULTS}

Taurine uptake by membrane vesicles prepared from 14-day or adult rat liver was examined in the presence of an inwardly directed $100 \mathrm{mM} \mathrm{NaCl}$ or $\mathrm{KCl}$ gradient (Fig. 1). For both age groups, the presence of a $\mathrm{NaCl}$ gradient stimulated the initial rate of taurine uptake and caused a transient accumulation of taurine above equilibrium. However, taurine uptake was significantly greater at all time points from 10 to $120 \mathrm{~s}$ with membrane vesicles prepared from 14-day compared to adult rats $(p<0.05)$. No significant age-related differences in $\mathrm{Na}^{+}$-independent taurine uptake as measured with a $\mathrm{KCl}$ gradient were detected (Fig. 1). These observations suggest that the $\mathrm{Na}^{+}$-dependent component of taurine uptake is increased in membrane vesicles from 14-day rat liver.

Previous studies in our laboratory have shown that there is minimal binding of taurine to membrane vesicles prepared from 
adult rat liver (8). To determine whether nonspecific taurine binding to the membrane contributes to the observed age-related differences in taurine uptake, the effect of medium osmolarity on taurine uptake was assessed using membrane vesicles from developing rat liver (Fig. 2). Similar to results previously observed using membrane vesicles from adult rats (8), taurine uptake by membrane vesicles from developing rat liver decreased with increasing medium osmolarity and extrapolation of the derived linear regression curve to infinite osmolarity (theoretical intravesicular volume $=0$ ) showed minimal binding of taurine.

To exclude the possibility that more rapid dissipation of the $\mathrm{Na}^{+}$gradient in membrane vesicles from adult rat liver causes a decrease in taurine transport, uptakes were measured with equal intravesicular and extravesicular sodium concentrations (Fig. 3). Under these $\mathrm{Na}^{+}$equilibrated conditions, taurine uptake remained significantly greater using membrane vesicles from 14day compared to adult rat liver.

The kinetics of sodium: taurine cotransport were examined in the presence of a $125 \mathrm{mM} \mathrm{NaCl}$ gradient using voltage clamped vesicles. Under these conditions, $\mathrm{Na}^{+}$-dependent taurine uptake (defined as the difference between taurine uptake measured with a $\mathrm{NaCl}$ gradient and a $100 \mathrm{mM} \mathrm{KCl}$ gradient), was linear for $9 \mathrm{~s}$ (8). For both age groups, the initial rate $(5 \mathrm{~s})$ of $\mathrm{Na}^{+}$-dependent taurine uptake measured as a function of extravesicular taurine concentration demonstrated saturable kinetics. The kinetics of sodium: taurine cotransport using LPMV from adult rats have

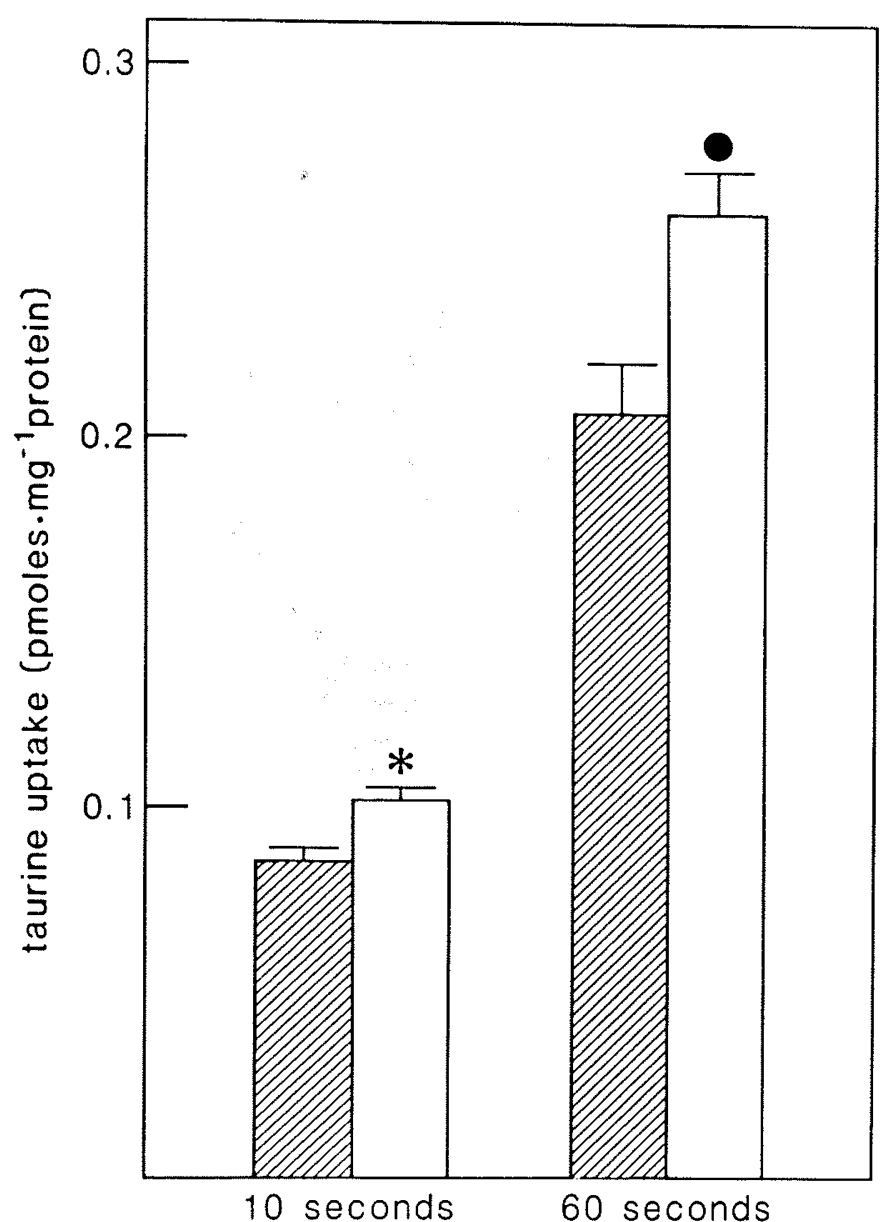

Fig. 3. Uptake of $\left[{ }^{3} \mathrm{H}\right]$-taurine $(1 \mu \mathrm{M})$ at $37^{\circ} \mathrm{C}$ measured with equal intravesicular and extravesicular $(100 \mathrm{mM})$ concentrations of sodium using membrane vesicles prepared from adult (hatched bars) or 14-day (open bars) rat livers. Vesicles were preloaded with $100 \mathrm{mM} \mathrm{NaCl}$. Final reaction mixtures and stop solutions contained $100 \mathrm{mM} \mathrm{NaCl}, 150 \mathrm{mM}$ sucrose, and $10 \mathrm{mM}$ HEPES-KOH, pH 7.5. Data represent the means \pm SEM of quadruplicate determinations from four membrane isolates. ${ }^{*}, p$ $<0.05$ compared to adult; $\bullet, p<0.001$ compared to adult.

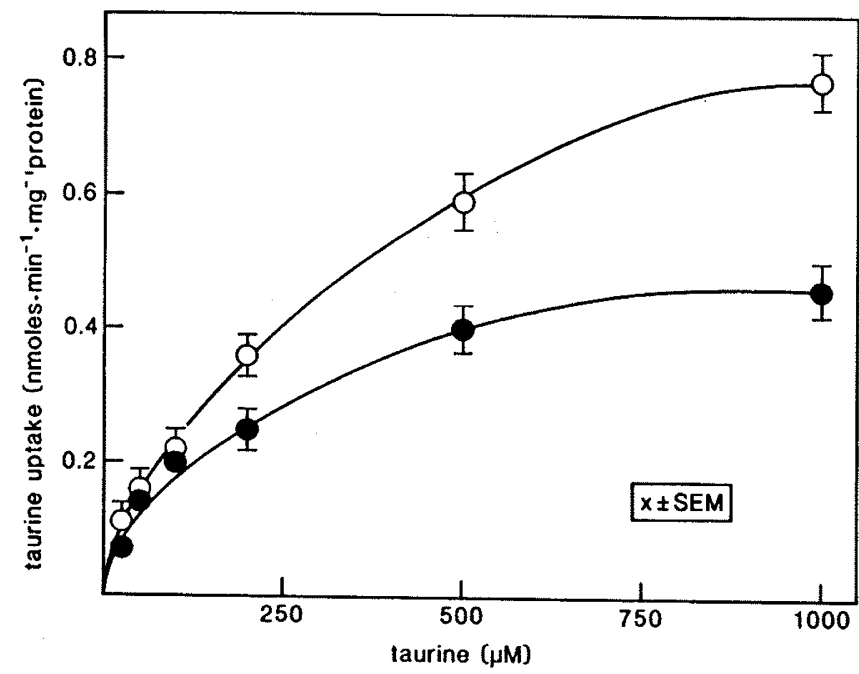

Fig. 4. Kinetics of $\mathrm{Na}^{+}$-dependent taurine uptake measured under voltaged clamped conditions at $37^{\circ} \mathrm{C}$. $\mathrm{Na}^{+}$-dependent taurine uptake is defined as the difference between uptake with a $\mathrm{NaCl}$ compared to a $\mathrm{KCl}$ gradient. Vesicles were preloaded with $50 \mathrm{mM} \mathrm{KCl}$. Reaction mixture contained varying concentrations of $\left[{ }^{3} \mathrm{H}\right]$-taurine $(25-1000 \mu \mathrm{M}), 125$ $\mathrm{mM} \mathrm{NaCl}, 50 \mathrm{mM} \mathrm{KCl}, 10 \mathrm{mM}$ HEPES KOH, pH 7.5, $62.5 \mathrm{mM}$ sucrose, and $5.0 \mu \mathrm{g} / \mathrm{ml}$ valinomycin or $\left[{ }^{3} \mathrm{H}\right]$-taurine $(25-1000 \mu \mathrm{M}), 150$ $\mathrm{mM} \mathrm{KCl}, 10 \mathrm{mM}$ HEPES-KOH pH 7.5, $112.5 \mathrm{mM}$ sucrose, and $5.0 \mu \mathrm{g}$ / $\mathrm{ml}$ valinomycin. Stop solutions were identical to reaction mixtures except for the absence of taurine and valinomycin. Best fit curve was generated using a computer program that performed a weighted least squares fit of individual data points to a rectangular hyperbola. Symbols represent the means of individual data points at a given concentration from at least three membrane isolates. $\mathrm{O}, 14$-day; $\boldsymbol{\bullet}$, adult.

been previously reported by us and are shown here for comparison to the kinetics of sodium taurine cotransport from 14-day rats (8) (Fig. 4). The maximum velocity of $\mathrm{Na}^{+}$-dependent taurine uptake was significantly greater using membrane vesicles from 14-day compared to adult rat livers (1.02 versus $0.54 \mathrm{nmol}$. $\mathrm{mg}^{-1}$ protein $\left.\cdot \mathrm{min}^{-1} ; p<0.001\right)$. The apparent $\mathrm{Km}$ was greater for developing compared to adult rat liver $(0.352$ versus 0.174 $\mathrm{mM} ; p<0.001)$. In contrast, $\mathrm{Na}^{+}$-independent taurine uptake measured with a $100 \mathrm{mM} \mathrm{KCl}$ gradient was linear for both age groups and no age-related differences were detected.

\section{DISCUSSION}

We have previously demonstrated the presence of a sodium:taurine cotransport system on the basolateral plasma membrane of adult rat liver ( 8 ). Taurine uptake by plasma membrane vesicles was found to be saturable, electrogenic, and stimulated by external chloride independent of the effects of this anion on the transmembrane electrical potential gradient (8). The findings herein suggest that the mechanism and driving forces for hepatic transport of taurine are similar in membrane vesicles prepared from 14-day or adult rat livers but uptake is significantly enhanced in the developing animal.

In LPMV from developing or adult rats, an inwardly directed $\mathrm{Na}^{+}$gradient stimulated the initial rate of taurine uptake compared with a $\mathrm{K}^{+}$gradient and provided the energy for accumulation of the amino acid above its equilibrium concentration (overshoot). The shape of the overshoot curve depends on a number of parameters including intravesicular size, the rate of dissipation of the electrochemical gradient for the driving ion, the affinity of the carrier for the ligand, the number of carriers available for transport and the mobility of the carrier in the lipid microenvironment (14). Any combination of these factors could contribute to the increased taurine uptake observed using membrane vesicles from 14-day compared to adult rat liver. Increased intravesicular volume will delay the occurrence but will not alter 
the peak height of the overshoot (14). For both age groups, the peak height of the overshoot for taurine occurs between 60 and $90 \mathrm{~s}$. Equilibrium values for taurine uptake are similar for both age groups consistent with previous studies that showed no significant age-related differences in intravesicular volumes (11).

Increased membrane permeability to sodium or the presence of other solutes using sodium cotransport systems will dissipate the sodium gradient and decrease the rates of transport (14). Sodium uptake is increased by approximately $25 \%$ using membrane vesicles prepared from adult compared to 14-day rat livers suggesting that the sodium gradient is more rapidly dissipated with membrane vesicles from adult liver (11). However, the present study demonstrates that taurine uptake measured with equal intravesicular and extravesicular concentrations of sodium is significantly greater using liver plasma membrane vesicles from 14-day compared to adult rats. These observations imply that age-related differences in taurine transport are not entirely due to more rapid dissipation of the sodium gradient in membrane vesicles from adult rat livers.

Kinetic analyses were performed under voltage-clamped conditions to minimize effects of electrical potential difference on taurine transport (15). The diffusional component of taurine transport as measured with a $\mathrm{KCl}$ gradient was similar using membrane vesicles from either age group. These findings show that differences in $\mathrm{Na}^{+}$-independent taurine uptake are not responsible for the observed differences in taurine transport. Increased affinity of the carrier for taurine will increase the peak height of the overshoot (14). However, the apparent $\mathrm{Km}$ for $\mathrm{Na}^{+}$-dependent taurine transport was significantly greater using LPMV from 14-day compared to adult rats implying the differences in apparent $\mathrm{Km}$ are not responsible for increased taurine uptake observed using vesicles prepared from the 14-day rat liver.

The maximum velocity of $\mathrm{Na}^{+}$-dependent taurine uptake was significantly greater using membrane vesicles from 14-day compared to adult rat livers. The Vmax depends on the number of translocator sites per $\mathrm{g}$ protein and the rate coefficient of translocation of the carrier across the membrane (14). The latter is a function of several factors including the electrical charge on the loaded and unloaded carrier and the composition of the lipid microenvironment $(14,15)$. The results herein do not distinguish between these possibilities. However, increased solute transport is not a general property of membrane vesicles from developing rat liver because we have previously shown that $\mathrm{Na}^{+}$-dependent bile acid uptake is decreased in developing compared to adult rat livers (11). These observations imply that the age-related differences in hepatic taurine transport are most likely due to an increased number of functional carriers in the 14-day rat.

The biosynthesis of taurine is decreased in most developing mammals due to reduced activity of the rate-limiting enzyme, cysteine sulfinic acid decarboxylase $(5,16)$. Although measurement of in vitro enzyme activity may not accurately reflect in vivo biosynthetic rates, the decreased CSAD activity observed during development implies that exogenous sources of taurine play an important role in maintenance of tissue stores (6). In the rat, taurine is one of the most abundant free amino acids in maternal milk with measured concentration ranging from 630 $\mu \mathrm{M}$ in early lactation to $200 \mu \mathrm{M}$ in late lactation (17). Several studies have not detected a transport system for taurine in membrane vesicles from adult intestine (18). However, the presence of a sodium:taurine cotransport system has been recently demonstrated in brush border membrance vesicles prepared from suckling rat jejunum (9). These findings support the contention that taurine is a conditionally essential nutrient during development.

The proportions of bile acid conjugates in bile depend on the availability of taurine and glycine and the relative affinity of $\mathrm{N}$ acetyl transferase for glycine or taurine. For many species, conjugation with taurine appears to be the preferred pathway. Because bile acid conjugation may be rate-limiting in the overall transport of certain bile acids, taurine availability might be critical to maintaining bile flow under certain conditions (19).
Taurine may also serve as a cytoprotective agent by detoxifying potentially cholestatic bile acids such as lithocholate or by acting as a scavenger for chlorine oxidants $(5,20)$. During development, maintenance of intrahepatic taurine stores could be of particular importance inasmuch as bile flow is already diminished and exposure to oxidant stress is increased $(11,21,22)$. In addition, taurine biosynthesis and the capacity of the kidney to retain taurine are decreased in the immature animal $(5,16,23)$. Under these conditions, an efficient transport system for taurine uptake from portal blood might prevent intracellular depletion of this $\beta$-amino acid.

In conclusion, the findings herein show hepatic taurine transport occurs by a sodium cotransport system and suggest that an increased number of functional carriers for taurine are present in the developing compared to the adult rat liver. Unlike other solutes (e.g. bile acids) taurine transport by the liver is well developed in early life perhaps reflecting the needs of the developing animal for this nutrient (24).

Acknowledgments. The authors acknowledge the excellent secretarial assistance provided by J. Carla Smith and the technical expertise of Charles Schmidt.

\section{REFERENCES}

1. Sturman JA, Hayes KC 1980 The biology of taurine in nutrition and development. Adv Nutr Res 3:231-299

2. Kuriyama K 1980 Taurine as a neuromodulator. Fed Proc 39:2680-2684

3. Thurston JE, Hauhart RE, Naccarato EF 1981 Taurine: possible role in osmotic regulation of mammalian heart. Science 214:1373-1374

4. Hayes KC 1985 Taurine requirements in primates. Nutr Rev 43:65-70

5. Wright CE, Tallan HH, Lin YY 1986 Taurine: biological update. Ann Rev Biochem 55:427-453

6. Huxtable RJ 1981 Sources and turnover rates of taurine in nursing and weaned rat pups. J Nutr 111:1275-1286

7. Huxtable RJ, Lippincott SE 1983 Relative contribution of the mother, the nurse, and endogenous synthesis to the taurine content of newborn and suckling rat. Ann Nutr Metab 27:107-116

8. Bucuvalas JC, Goodrich AL, Suchy FJ 1987 Hepatic taurine transport: characteristics of a $\mathrm{Na}^{+}$-dependent carrier on the basolateral plasma membrane. Am J Physiol 253:G351-G358

9. Moyer MS, Goodrich AL, Suchy FJ 1986 Ontogenesis of intestinal taurine transport: evidence for a $\beta$-carrier system in developing rat jejunum. Gastroenterology 90:1558(abstr)

10. Blitzer BL, Donovan CB 1984 A new method for the rapid isolation of basolateral plasma membrane vesicles from rat livers: characterization, validation and bile acid transport studies. J Biol Chem 259:9295-9301

11. Suchy FJ, Courchene SM, Blitzer BL 1985 Taurocholate transport by basolateral plasma membrane vesicles isolated from developing rat liver. Am $J$ Physiol 248:G648-G654

12. Lowry OH, Rosebrough NJ, Farr AL, Randall RJ 1951 Protein measurement with folin phenol reagent. J Biol Chem 193:265-275

13. Cleland WW 1979 Statistical analysis of enzyme kinetic data. Methods Enzymol 63:103-138

14. Heinz E, Weinstein AM 1984 The overshoot phenomenon in cotransport Biochim Biophys Acta 776:83-91

15. Barts PWJA, Borst-Pauwels GWFH 1985 Effects of membrane potential and surface potential on the kinetics of solute transport. Biochim Biophys Acta 813:51-60

16. Kuo SM, Stipanuk MH 1984 Changes in cysteine dioxygenase and cysteinesulfinate decarboxylase activities and taurine levels in tissues of pregnant or lactating rat dams and their fetuses or pups. Biol Neonate 46:237-248

17. Stipanuk MH, Kuo SM, Hirschberger LL 1984 Changes in maternal taurine levels in response to pregnancy and lactation. Life Sci 35:1149-1155

18. Stevens BR, Ross HJ, Wright EM 1982 Multiple transport pathways for neutral amino acids in rabbit jejunal brush border vesicles. J Membr Biol 66:213225

19. Zouboulis-Vafiadis I, Dumont M, Erlinger S 1982 Conjugation is rate limiting in hepatic transport of ursodeoxycholate in the rat. Am J Physiol 243:G208G213

20. Dorvil NP, Yourset IM, Tuchweber B, Roy CC 1983 Taurine prevents cholestasis induced by lithocholic acid sulfate in guinea pigs. Am J Clin Nutr 37:221-232

21. Srai SKS, Burroughs AK, Wood B, Epstein O 1986 The ontogeny of liver copper metabolism in the guinea pig: clues to the etiology of Wilson's disease. Hepatology 6:427-432

22. Suchy FJ, Courchene SM, Balistreri WF 1985 Ontogeny of hepatic bile acid conjugation in the rat. Pediatr Res 19:97-101

23. Chesney RW, Gusowski N, Theissen M 1984 Developmental aspects of renal $\beta$-amino acid transport. IV. Brush border membrane response to altered intake of sulfur amino acids. Pediatr Res 18:611

24. Gaull GE 1983 Taurine in human milk: growth modulator or conditionally essential amino acid? J Pediatr Gastroenterol Nutr 2:5266-5271 